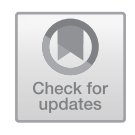

\title{
Inflexions of Deleuze|Guattari: For a New Ontology of Media, When West-East Meet
}

The philosophical importance and impact of Deleuze|Guattari are experiencing a strong interest in Asia. In 2013, Tamkang University in Taipei Taiwan, under the directorship of Hanping Chiu held the First International Asia Conference on Deleuze. Korean scholars were among its participants. In 2014, Japan's Toyonaka University, in Osaka, hosted the second International Deleuze|Guattari conference with theme of "Islands." In 2014, Delewze and Asia (Bogue et al. 2014) published papers from the Taipei conference. The Deleuze-Asian connection continues. Before this sudden uptake, there has been a trickle of essays that show the links between Deleuze|Guattari and Zen-Tao (Maliavin 2011; Vodka 2013; O'Sullivan 2014a; Zhang 2016). It is to the credit of Korean Society of Education Through Art (KoSEA) to continue to recognize the importance of this line of thinking for the twenty-first century by hosting the 13th KoSEA International Conference on October 26, 2013, under the title: Nomadism, Art, and Art Education. This chapter addresses insights a Deleuze|Guattari understanding can bring to art and its education especially for the twenty-first century, a time of

A different version of this paper was first published 2014. 6 Journal of Research in Art Education (KoSEA), 13(2): 1-22. It was delivered as a keynote presentation on Oct 26, 2013 for the 13th KoSEA International Conference entitled Nomadism, Art, and Art Education.

(C) The Author(s) 2020

j. jagodzinski, Pedagogical Explorations in a Posthuman Age,

Palgrave Studies in Educational Futures, https://doi.org/10.1007/978-3-030-48618-1_2 
continued rapid technological change, capitalist globalization, and the planetary disaster of 'climate change.' The future of education depends on how we, as artists and teachers, address these questions with our children and students who face such difficult issues. Youth around the globe expect a response despite the lack of initiative by many of the key global leaders, most notably Donald Trump. Greta Thunberg has been elevated to the post as the leading youth activist and spokesperson. She has managed to spearhead the Fridays for Future (FFF) movement where students in many major cities around the globe skip school in their attempt to rally together and send a message to their legislators.

The philosophy of Deleuze|Guattari forms a bridge between Taoism that is pervasive in the East and a revival of non-representational thought in the West by what generally has been called materialist transcendental philosophies. The influences between them are obviously rhizomatic in the Deleuze|Guattarian sense. "If I had been born in China, I would have been a calligrapher, not a painter," Picasso once famously said, hinting that there has always been an artistic exchange between East and West. The complexity and interrelationships that exist between Taoism and Deleuze|Guattari philosophy require scholarship to explain the many difficult concepts that, at times, seem tenuous; nevertheless, they open up interesting questions. This is remarkably illustrated by Amir Vodka (2013) who makes the claim that the cinema of kung fu can be related to Deleuze|Guattari's Body without Organs via Tao, which forms its own kind of $\mathrm{BwO}$ as "the shape that has no shape, the image that is without substance" (Lao-Tzu 1963: 18). When Deleuze|Guattari ask, "is the Tao masochist?" (TP, 1987: 174), the answer is that pain, torture, and restraint are part of the kung fu master's 'way' to absolve his ego and provide a way to reconfigure his/her BwO. "The masochist uses suffering as a way of constituting a body without organs and bringing forth a plane of consistency of desire" $(T P, 172)$. While Vodka refers to the famous films of Bruce Lee, Marvel's TV series Iron Fist is equally instructive, as the narrative follows Danny Rand as he searches for his identity, quelling his anger to focus his Chi (material force of free energy) into the part-object as weapon: his fist. The intensive body without organs is Tao, while iron fist becomes a channeled 'bloc of sensations.' Vodka argues that 'becoming animal' is quite prevalent in many kung fu movies. It is taken up in Chapter 5 with the cinema of Kim Ki-duk, while 'becoming insect' is sequentially illustrated in Chapter 10. 
'Becoming imperceptible' is equally at play in kung fu cinema when new potentials emerge from the virtual, and reality then changes through such events. Vodka draws on the Matrix, and such digitalized effects like 'bullet time' to show how for Neo, the hero who 'wakes' up to a new reality is able to discern all durations that coexist on a shared plane of consistency-durations that are at once too slow and too fast, enabling him to dodge bullets as he is too fast for them (and they are too slow). This is 'suspended time,' the time of Aion-the living present "precisely where the imperceptible is seen and heard" (TP, 278). In brief, digital cinema in this case is able to visualize the imperceptible as pure movement, an abstract plane understood as any-plane-what-soever that traces movements. There are only relations of its singularities. We can point to the artwork of Morgan O'Hara to illustrate what is being inferred. Her 'scribble-art' presents the performative line drawings of a generic human, which are imperceptible movements that emerge through her translations of her Lebenswelt. What is mistakenly taken to be the most extreme example of abstract art is in fact the most concrete. Her drawings capture only movement, drawn at speeds with things she 'vibrates' with. This is not her 'translating' life experiences; rather, it is a collapse of subject and object, a direct expression. François Laruelle (see Galloway 2014: 153-215) says as much and illustrates this same phenomenon through the pencil-music drawings of August Von Briesen. While these drawings give graphical forms to musical sounds via lines, dashes, points, variations in length, line weight, width, orientation, curvature, and so on, a clear case of synaesthesia (see Chapter 9 in this book), Laruelle takes this a step further. Von Briesen's syncretism is an "automatic registration" of the Real itself.

Imperceptibility in this sense is a difficult concept. If it is analogous to an Outside Real, then it also has affinities with Lacan's objet a; something from the outside, something imperceptible and non-categorizable makes us think. This part-object (like the iron 'fist') would be an "automatic registration" of Chi much like Von Briesen's pencil drawings, who generated as many as 10,000 of these gestures a year! 'Becoming imperceptible' is performative. It calls forth the experience of time, which Deleuze, following the Stoics called Aion (as opposed to Chronos) and, in Taoist thought, referred to as 'pure' time, beginning-less, yet non-eternal. The Tao is understood as a concept that can simultaneously hold opposite values. Time is immanent, yet never changes. It has no beginning, yet it is not eternal; most 
strange of all: it is everything, yet it does not even exist. Aion sustains this same idea of infinite time, the 'gaps' between past and the future. In quantum physics, the smallest imaginable unit of time is Plank time $\left(5.4 \times 10^{-44} \mathrm{sec}\right.$. $)$ and Plank distance $\left(10^{-33} \mathrm{~cm}\right)$. At that point, time and distance become meaningless. In mathematics, continuous and discontinuous numbers remain complementary, the paradox repeating energy as both wave and particle. There is no unifying mathesis universalis.

As Deleuze maintains, self and other, subject and object, outside and inside collapse into an empty present, "which is subdivided ad infinitum into something that has just happened and something that is going to happen, always flying in both directions at once" (Deleuze 1990: 65). The sequence of the living present is sustained by the 'Tao' of time, "which divides it [the present] eternally into a proximate past and an imminent future" (ibid.: 63). The Tao, like 'becoming' itself, is both permanent and impermanent. The second chapter of Tao Te Ching (see Moeller 2006) states:

Therefore having and not having arise together.

Difficult and easy complement each other.

Long and short contrast with each other;

High and low rest upon each other;

Voice and sound harmonize each other;

Front and back follow one another.

Performance artists place themselves into such a time, and by doing so, they become imperceptible to themselves as they move in this virtual gap, or virtual Real of chronological time. They emerge changed after the performance. This is precisely where 'true' creativity occurs, but it is also the moment of greatest risk where life $=$ death becomes a 'cut' in the fabric of the actual.

The Deleuzian 'w(hole),' as an open-becoming, has affinities with the Taoist zero; it is the Open, the impossible 'set of sets,' without exteriority. Neo in the Matrix should be regarded as a singularity, a 'zeroness' of the $\mathrm{BwO}$, an Open Whole, perhaps best understood by their formula: PLURALISM=MONISM. Here, we can push Deleuze and Guattari even further by suggesting a quantum twist to their claim by maintaining that this 'monism' is also an infinite "multiverse," as a majority of physicists claim. As a true infinite, the multiverse (as 
Tao) is both Everything and Nothing, or 'happening' itself of infinite creation: pure potential. Our universe is just one of many, which supports a Taoist notion of the permanence as well as the impermanence of time. Even the notion of rhizome's nonlinearity, non-hierarchy, and multi-dimensionality is not a simple task to comprehend, but describes the relationships and principles of Tao, and the sensibility to Chaos through the creativity of 'non-action,' as Wu Wei (non-doing, or doing nothing, to be in the flow, to be imperceptible). Intentionality becomes transformed into intuition. Intuition holds no rigid and set plan as much as a direction of speed and slowness. Yet, the paradox is that this requires a repetition of practice, and in that practice, to discover always anew. The artistic process is intuitive rather than strictly methodological. Overcoming dualisms, stressing creativity as affirmation, and overcoming transcendentalist thought are shared by both philosophies. As Deleuze and Parnet (2007) puts it:

It would not be enough to oppose the East and the West here, the plane of immanence which comes from the East and the plane of transcendent organization which was always the disease of the West, for example, eastern poetry or drawing, the martial arts, which so often proceed by pure haecceities and grow from the 'middle.' The West itself is crisscrossed by this immense plane of immanence or of consistence, which carries off forms and strips them of their indications of speed, which dissolve subjects and extract their haecceities, nothing left but longitudes and latitudes. (94, added emphasis)

The Korean scholar, Hyeyoung Maeng (2020) has provided many parallels between Deleuze's process ontology and the practice of Korean Bunche painting. She shows that many of their concepts can be transposed and illustrated through this painting process. Perhaps more impressive are Maeng's (2017) many attempts to provide the linkages to Tao in her impressive doctoral thesis. There she notes, in A Thousand Plateaus there are many passages that confirm such rich parallelism. Deleuze|Guattari describe the Tao as "a field of immanence in which desire lacks nothing and therefore cannot be linked to any external or transcendent criterion" (157). Where Yin and Yang are processes of stratification and destratification, while the state of Tao as the plane of consistency can be thought of as "the totality of all BwO's, a pure multiplicity of immanence" (158). 
There are many more parallels, of course. Both Taoism and Deleuze|Guattari are process philosophies: they are about change and becoming, and not about being and representation. It is very difficult to articulate the significance of Deleuze|Guattari for art and its education in any simple and easy way. There is no 'method' for art, only emergent processes that are not always successful; there is no 'research' in art as is so often wanted, only 'research creation.' The second stanza of Chapter 2 of Tao Te Ching states:

Therefore the sage goes about doing nothing, teaching no talking.

The ten thousand things rise and fall without cease,

Creating, yet not possessing,

Working, yet not taking credit,

Work is done, then forgotten.

Therefore it lasts forever.

Research creation in art speaks to 'the Way' in Tao. As Lieh-tzu (Graham 1990) says: "Will the Way end? At bottom it has had no beginning. Will there never be more of it? At bottom it does not exist?" (22-23). James Elkins (2001) once wrote a book maintaining that art cannot be taught. Artistic research creation presents this paradox of $c$ reation by artists who never 'arrive,' are never finished, and are constantly 'on their way,' searching for 'the Way,' which does not exist, working with contingencies, surprises, accidents so as to enter a zone of imperceptibility: becoming-impersonal, becoming-indiscernible.

The Tao also seems to address the plane of immanence (or plane of consistency). As Deleuze and Guattari (1994) put it in What is Philosophy: "The plane is clearly not a program, design, end or means: it is a plane of immanence that constitutes the absolute ground of philosophy, its earth or deterritorialization, the foundation on which it creates its concepts" (41). We read in the book of Lieh-tzu: "There was Primal Simplicity, there was Primal Commencement, there were Primal Beginnings, and there was a Primal Material. The Primal Simplicity preceded the appearance of the breath. The Primal Commencement was the beginning of the breath. The Primal Beginnings were the breath beginning to assume shape. The Primal Material was the breath when it began to assume substance. Breath, shape and substance were complete, but things were not yet separated from each other; hence the name 'Confusion.' 'Confusion' means that the myriad things were confounded 
and not yet separated from each other" (18-19, Graham's translation). Confusion and chaos, what Félix Guattari called 'chaosmosis,' appear to be the same concept, while the virtual provides for the quantum notion of superposition: the potential configurations of an assemblage-as an arrangement of particles or fields - that actualize as singularities within specific ecologies. Thinking this way avoids considering only a 'big bang' theory of the universe-that is, a Plank epoch or Plank era that starts the arrow of time (e.g., 13.8 billion years). Rather, it suggests a multiverse as a timeless state of indeterminacy, closer to a Hartle-Hawking universe, which claims it an emergent singularity. It is precisely singularity or an event, as Deleuze and Guattari stress, that generates form. Perhaps the emergence comes from black holes, for it is in these w(holes) where chaos as 'confusion' reigns supreme; it is precisely here where light is bent and gravitational force becomes the stumbling block to complete the search for an all-encompassing unification of quantum mechanics and general relativity as a 'Theory of Everything' that would combine the four known forces together: gravity, electromagnetism, the weak, and the strong interaction. It is the quantum nature of gravity that remains enigmatic and allusive in this quest (Snaches 2019). It is not difficult to see how Deleuze|Guattari envision a cosmology and the interplay of the cosmological forces of chaos as inorganic energy (unleashed energy, Zoë), a pure BwO, the Tao of Zero, Laruelle's One (a radical Real), the 'given as given,' and the material force of Chi (Ki) of Tao, and so on, where 'mad' particles abound.

\section{Against Representation}

For those who have tried to read Deleuze|Guattari will readily testify how difficult this task can be. One doesn't comprehend their writing style or philosophy easily. Yet there has been an explosion in various areas concerning their work in virtually every scholarly area: including literary studies, cinema, education, urban planning, literary studies, architecturethe list goes on. Perhaps the most significant shift by scholars who have embraced their work has been the realization that representational thought dominates most disciplines globally, and this needs to be urgently and constantly questioned. Artistic research in particular needs a complete rethinking here where thought and image are in tension with one another (see especially Vellodi 2019). In the field of art education, this is particularly true when it comes to visual cultural studies a sub-discipline 
that emerged out of cultural studies. (I discuss this development in Chapter 8.) Here, the usual approach of representational thinking is to understand difference always in relation to sameness. This is a very seductive way of thinking as it appears that social equality is being pursued, and that justice is being achieved as the question of human rights is meant to put everyone on an equal footing. From a Deleuzian standpoint, representational thinking simply reinstates inequality by masking the situation. Representational thought places the question of the Other, either too far or too close. What do I mean by this? By 'too close,' difference is masked under a humanist universalism: we are (after all) all the same despite our differences. But, despite these differences, we somehow 'know' or try to 'know' and understand the Other. We are 'like' them, and we try to communicate and get to know them despite the gulf between us, because, in the end, we are all 'human beings.' Such a stance generates fantasies of compassion by maintaining distance, for it is we, after all who are reaching out to the Other and trying to grasp their identity. It is not them who are reaching out to us. For a trained anthropologist, this seemed to be a commonsensical approach. After all, the intent is to get an inside ethnographic view to close the distance. Ideally, this would lead to becoming the Other, but when this happens, if the collapse is complete, then 'differences' are no longer discernible. "Going Native" now becomes ideologically questionable as does the question of 'cultural appropriation.' Artists such as Paul Gauguin, Emily Carr, and 'Haida' artist Bill Reid have all been criticized for getting 'too close' so that the self-Other gap is reinstated and identity preserved.

By being 'too far' from the Other moves in the opposite direction. This means "we" are "unlike them," or unlike the Other, so we must remain silent in relation to what is alien; otherwise, we do away with their difference, or interfere with it. This leads to fetishization and exoticization of the Other because it is this very difference that supports our fantasies. This is how difference always forms a dualism with sameness. Representational thinking, through this either-or logic always, generates a hierarchy in relation to the structure of sameness and difference. The Other's difference is always 'used' to position the relationship in unequal ways on the grounds that equality is being pursued. Theorists like Balibar (1992) called this post-racism, neo-racism, and even cultural racism. Let me offer an illustrative example. 


\section{EXPOSING BENETTON}

There is a rather ingenious advertisement by Benetton. It shows three hearts, which are similar but slightly different. They are images of pig hearts but they seem human enough as photographed by the Italian designer Oliviero Toscani in 1996, who spearheaded its 'The United Colors of Benetton' campaign. Benetton has since cut ties with Toscani in 2020 over his remarks concerning the collapse of the Morandi bridge in Genoa. (I encourage the reader to look up this image on the Internet as copyright laws prevent me from including it in this chapter.) Despite their minor differences, the three images fall under the categorical signifier 'heart.' Each heart, however, has another signifier that 'represents' a race in an essentialized way in terms of identity formation: white, black, and yellow are the colors that signify three different races. The implication being that all three races, beneath their skin, are equal or the same. At first glance, this is a very seductive advertisement, for it appears that Benetton is certainly making a claim as to the inequality of the 'surface' color and comparing it with the 'depth' of bodily organs where we are all the 'same.' We all have 'heart.' We are all 'human' says the advertisement despite the color of our skin and despite that these are animal hearts. So, how can this possibly be 'post-racist' advertisement? This seems counter-intuitive.

Differences (as particularities) are contrasted to the generalization of sameness: we are all of the species homo sapiens (or 'pigs' in this case!). Difference in-itself, as singularities, is what is negated, and it is precisely this oversight that Deleuze|Guattari attempt to overturn. They base their philosophy on pure difference alone. When negation happens (as discrimination for instance), the idealization of homo sapiens at a physical level of idealization is then 'smuggled' in. This has been the primary problem with the signifier 'human': who belongs and is given privilege and access to this category? Like the hearts in this advertisement, it appears to be an all-encompassing inclusive category, yet we know historically who is justified by this signifier is selective and exclusive: the most obvious examples are women, indigenous peoples, and African Americans. They quickly come to mind, but the entire post-colonial landscape is shaped by this exclusionary term, human, that appears inclusionary. The advertisement appeals to an impossible category of equality called 'human,' which is endlessly discriminated against due to the logic of the multiple binaries 
it generates within the sameness-difference logic of representation based on the purity of visible color: red, white, yellow. Such color boundaries become troubled very quickly when shades, tints, and tones come into play; their intensities of affect begin to blur boundaries between colors, introducing confusions of 'distancing' and 'passing' which representational identities present politically and ethically. Deleuze, in Difference and Repetition (1994), succinctly listed four postulates of such logic: (1) identity, (2) opposition of predicates, (3) analogy when it comes to judgment, and (4) resemblance in perception.

When it comes to Benetton's Unhate Campaign (again, I encourage the reader to find these images on the Internet), all the President of the United States (Barack Obama at the time) and the Former General Secretary of the Communist Party of China (Hu Jintao) have to do is simply kiss each other. Collapse distance and then world harmony will begin. All will be forgiven. This is a very Hegelian move: two opposites come together (thesis and anti-thesis) and an Aufhebung will take place, elevating the contact to a higher plane of resolution. Simple, isn't it? Love overcomes all, in this case homoerotic love. But just how races (or nations, or ethnicities, or women, or men and so on) are the same, overcoming their dichotomous binds, remains a representational illusion. This is a transcendental ideal that can never be reached. The physical heart, just like the 'kiss,' is itself an ambiguous sign that says we are all biologically the same when we know that there are psychocultural differences that cannot be easily dismissed. Traumas that prove too deep to be flippantly done away with. The Judas 'kiss' of betrayal is repressed. North Korea and South Korea present this difficult paradox of difference and sameness.

There is a half-truth to the Unhate Campaign, which again makes it so seductive. Bodies do affect each other. "We do not know what a body can do," a phrase that is so often repeated in the secondary Deleuzian literature. This was Deleuze's great insight when he embraced Spinozian philosophy. Unquestionably, great diplomacy can overcome what are impossible differences, even when they are in the end thwarted, as happened when Bill Clinton brokered a peace agreement (the Oslo Accords) in 1993 between Israel's Prime Minister Yitzhak Rabin and the leader of the Palestine Liberation Organization (PLO) Yasser Arafat. Two years after, in 1995, Rabin was assassinated at the Kings of Israel Square in Tel Aviv for his moderate liberal views by a radicalized right-wing rabbi extremist. East Asian cultures tend to define the self in 
relation to a group or collective whereas within Western cultures there is greater emphasis on the self to be viewed as unique and independent of the social group. In these Benetton advertisements, the assumption is made that (1) races are categorical, there is no overlap, and (2) they resemble one another on the physiological level. We all have 'heart,' and therefore (3) we are all equivalent under the general law that we are 'human beings' capable of great compassion and care. True. Especially when it comes 'to our own.' This is the commonsense view that is continually reproduced in the current image of thought, especially in multicultural societies where there is a deep need to 'tolerate' differences under an assumed sameness of equality by human rights legislation. "Diversity," as Deleuze (1994) argued, "is not difference. Diversity is given, but difference is that by which the given is given, that by which the given is given as diverse" (222). Diversity is rather the negotiation of distances and toleration for the Other within representational logic. For Deleuze, thought as reproduction, the common image of thought simply affirms identity; it is thought that produces the new images that are not in circulation, which stimulate and create the new. Benetton manages to stabilize differences along colored lines via a universal ideal, or generalization that, on its surface, seems perfectly fine, but that means erasing all 'differences' as singularities so that we end up with really nothing at all in relation to justice, rights, equal treatments, peace rather than war, and so on. Identity politics continues to sustain its affective force.

Difference in representational thought is always in relation to a conceived identity; it is a judged analogy (the Other is too close) or an imagined opposition (the Other is too far). For Deleuze, thinking in terms of generalities and particulars operates within the limits of representation, which is a "transcendental illusion." "I think' is the most general principle of representation" (Deleuze 1994: 174). This means that the human subject 'grounds' knowledge in relation to a metaphysical notion of an outside reality, as if a thinking subject is able to transcend and represent the meaning of an object (e.g., culture) in accordance with an external reality. The authority of the subject is always in play to establish truth claims. Deleuze|Guattari are against any forms of identity as the "dogmatic image of thought." All representational thinking presupposes a subject-object gap, a 'correlationism' (Meillassoux 2008). Our consciousness produces images from or of things that our perception grounds in representation. This is the Kantian axiom where the transcendental field is in the image of the empirical 
field. "I think" is added so that a transcendental ego is shaped; there is a "Transcendental Unity of Apperception," and thus a distinct anthropocentrism established to all judgments. Deleuze, on the other hand, maintains that this transcendental field remains differential, impersonal, and pre-individual. The condition for 'real experience' is virtual, which has no identity. Correlationism is already the product of actualization of this prior differential field.

Against representational thought of any kind, Deleuze|Guattari develop a philosophy of becoming where time is always a factor (as discussed above). Like the Tao, which says, "The movement of Tao is to return; The way of Tao is to yield" (Verse 40, Tao Te Ching) (Lao-Tzu and Takuan Sōhō 2010). In Anti-Oedipus (1983), Deleuze|Guattari draw on the figure of the schizo as exemplifying such an ego-loss, a yielding: "[the schzo who practices a psychic minorization] produces himself as a free man, irresponsible, solitary, and joyous, finally able to say and do something simple in his own name, without asking permission; a desire lacking nothing, a flux that overcomes barriers and codes, a name that no longer designates any ego whatever" (131). This suggests the creativity of singularity, of becoming imperceptible. The Tao of Zen seems to follow this: "[n]othing remains the same for two consecutive ksanas (the shortest imaginable periods of time)" (Hanh 1995: 39). Nothing has a fixed representational identity, what persists is the paradox of difference itself.

\section{The Performativity of the Image}

The most sophisticated forms of representation are the performative and constructivist approaches to subjectivity as exposed by Michel Foucault's discourse theory. Representation is considered in terms of what it does and not in terms of truth or accuracy; the question is how both the subject and the object are mutually structured or constructed by a discourse. The discursive image implies an ideal subject position or an Ideal Ego in Lacanian terms, and asks the spectators to emulate or take part in this image through their own ego ideal. Here the performative notion of the image is usually shaped cleverly by and through company image or logo branding.

A brilliant example comes from the country of Peru that re-branded its national identity in the globalized world. In what is a case of reverse post-colonialism, a busload of well-known Peruvians-actors, dancers, 
and chefs-traveled to Peru, Nebraska in the United States to sell the Peruvian culture to a population of 569. Nebraskans danced, ate Peruvian food, and learnt a few words of Spanish. This delightful 'invasion' can be viewed on YouTube https://www.youtube.com/ watch?v=tOR3lhyMOcU. It is a marvelous example of performative and representative notion of the image: what it can 'do,' that is, the power of its affect to influence and shape desire. What an image's effects are for global capitalism is what Deleuze|Guattari worry about as Deleuze (1992) briefly mapped out in a short article on a 'societies of control' that draws on the capacity of third-generation cybernetics to program algorithms to run smart machines (as discussed throughout this book). When it comes to performative imagery, the subject is never certain. One has to be lured into comply with an Ideal Ego that is being offered. The inhabitants of the small village of Peru, Nebraska have to identify with something that is ideally, essentially, and nationalistically Peruvian in Latin America to insure recognition of the Peruvian logo that categorizes their difference (as diversity). What is 'different' as abject is meant to turn into its opposite, as something that becomes acceptable, even enjoyable, and thereby increasing the comfort level of being with the Other. Its performative affect is thereby achieved.

This is the repetition of difference in the postmodern sense. The so-called interactive social media attempt to continually adjust what customers and spectators are saying, voting, tweeting, posting, and so on, so that the discursive formation of the Ideal Ego can be maintained by the company, state, or those in charge. Management becomes a huge industry while prosumers do their bidding inadvertently. In a modulated society of control, says Deleuze (1992) and Guattari, consumers become produces and vice versa in a never-ending look to maintain some sort of structure so markets are stable within certain degrees of freedom. As Judith Butler (1990) has developed this, the performative (or active) notion resides in the possibility of always contesting the Ideal Ego image: the so-called norm or ideal is always changing historically. The problem is that such resistance or protest is always co-opted inside this machine; the negative resistance fuels change through conflict, if only to reverse trends in a never-ending question to have equity and equality that can never be achieved, a metaphysical ideal. There are/were 'accelerationists' like Nick Land in the 1990s (Warwick University) who thought that speeding up the cyber-technology invented by global capitalist system would lead eventually to its collapse via a 'cyberpunk phuturism' complete with a 'zombie 
apocalypse.' Although this wasn't likely to be the case, one wonders today about such a scenario when SARS 2 (COVID-19) has been let lose? Land's 'Dark Enlightenment Manifesto' (2012) continues to be thought provoking if not an earth-shattering view of a dystopian capitalist future. Simon O'Sullivan (2014b), with strong roots to Deleuze|Guattari, has attempted to provide a strong and worrisome assessment of accelerationist thought as has Benjamin Noys (2014). But, on to more humous note.

An intentionally funny and ironic example of this never-ending quest for equality in representational terms comes from the American film culture. The film, The Lone Ranger (2013, d. Gore Verbinski) (Screen image 2.1), based on a well-known television series in the 1950s (Screen image 2.2), was meant to intervene in the myth of the Wild, Wild West in order to subvert the historically inequitable Indian|White Man relationship. Try as the film might, the exotic First Nations 'warrior,' Tonto (played by Johnny Depp), set up as the true brains behind the Lone Ranger (played by Armie Hammer), was just not convincing enough. The film was a flop. Identity politics around gender, sex, ethnicity, race, and so on is continually in flux in representational thought. The 'Hollywood' solution to this is to work out a politically correct neutrality by having 'one of each' so to speak, for equal

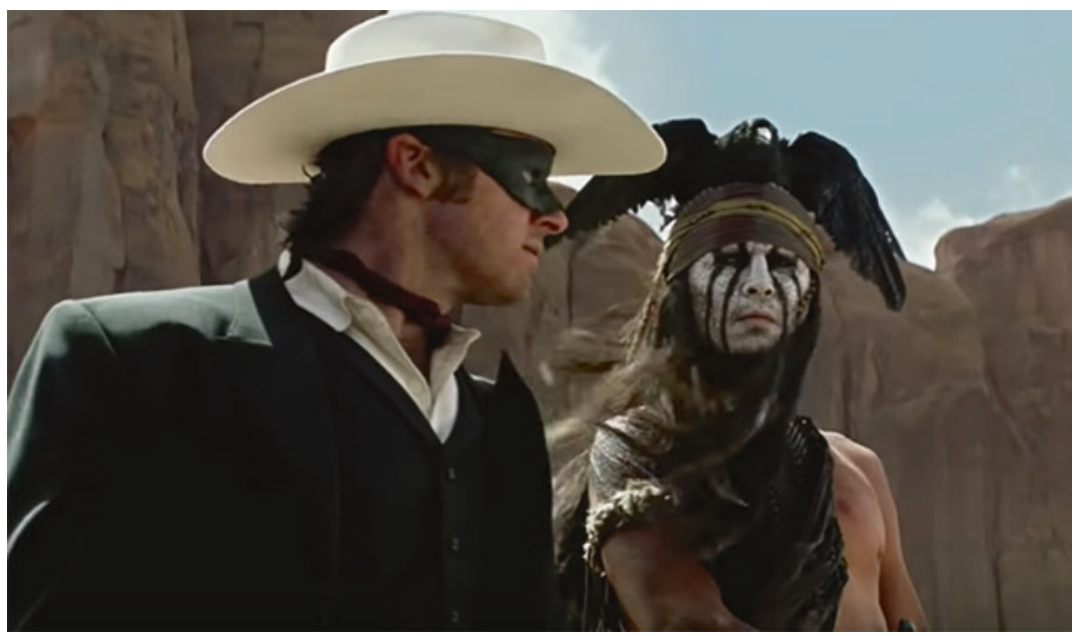

Screen image 2.1 Lone Ranger (2013) 


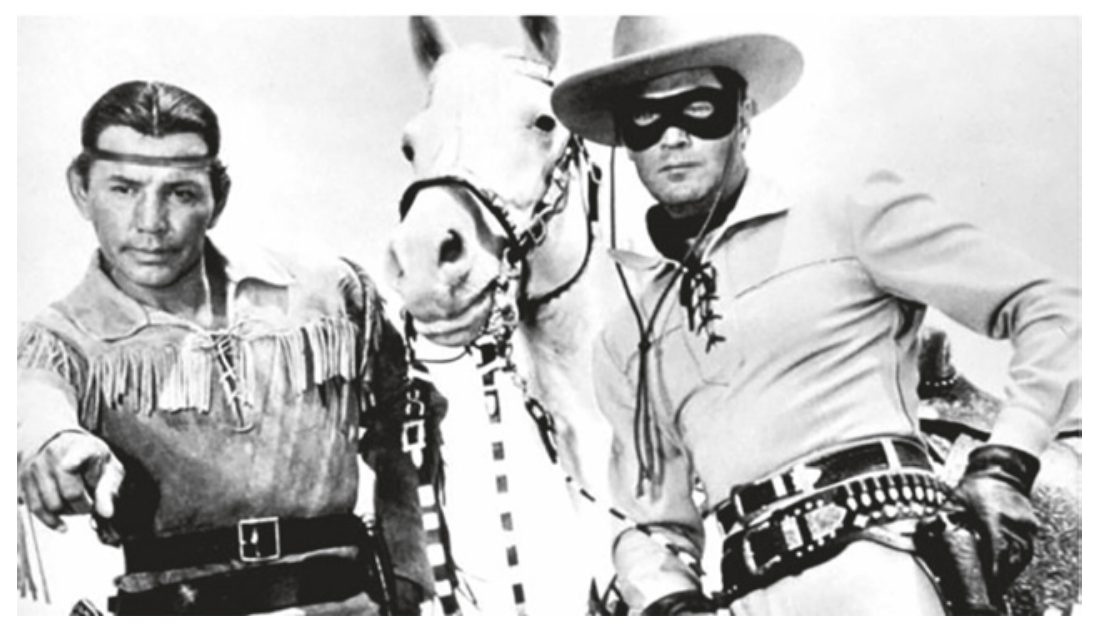

Screen image 2.2 Lone Ranger, TV series 1950s

representation. Hence, an equal number of men and women, or an equal number of races represented in films. Companies like Disney have become particularly sensitive to such political correctness.

Again, this is precisely what Deleuze|Guattari in TP attempt to dispel and query. They introduce the term 'minoritarian' rather than minority to worry and confuse the numerology that majority-minority dualisms represent. Minoritarian is always an ethico-political positioning that requires action when challenging power and discrimination to deterritorialize itself from the majority, and hence not necessarily bound by number. It marks the potentiality for change through a new becoming or singularity. Most of art and its education are structured by this "transcendental illusion." The power of Deleuze|Guattari's shift is to a position beyond representation, toward anti-representationalism that strives to think beyond all subjectivism, to free thought of the illusion of transcendence. In this sense, Deleuze|Guattari are closer to Eastern thought than Western, which remains caught by representation. Deleuze|Guattari drew on what was a "minor philosophy" in the West-Spinoza, Whitehead, Nietzsche, Hume-to develop non-representation processes of creative becoming. Of course, it must be understood that an encounter with art that creates thought is not an experience that is decided in advance; its advent cannot be planned. Deleuze|Guattari reserve the term becoming 
imperceptible (as developed above) where what is experienced cannot be recognized; a limit is reached when common sense becomes unhinged. For Deleuze|Guattari, this is an indication that an event of art, an encounter has indeed taken place. A thought without image has been engendered, which gives a hint of what 'imperceptibility' is about.

\section{Repetition with a Difference}

One of the main concepts Deleuze develops against representational thought of any kind is that of the simulacrum. The most common notion of a simulacrum is a copy of a copy, like photorealism where the painting is a copy of a photograph, which itself is a copy or representation of the world 'out there' that acts as the originating model. Whereas a copy is made to stand in for its model, simulacra as repetitions of the model introduce a difference that turns against the 'original' in order to open up a new space and a new world. It affirms its own difference and unfolds a multiplicity of new problems and solutions. It is what Deleuze refers to as the powers of the false. Simulacra are non-representative because they are nothing but appearances-just 'qualities' of things as part-objects. There is nothing 'behind' the image.

The will to art (Kunstwollen) consists of extracting differences from repetition by reversing copies into simulacra. Art neither represents nor imitates because it simply repeats. Everyday life is characterized by repetition, as a return to the same, through habit, primarily through standardized production of commodities and the proliferation of information. Art, from a Deleuzian standpoint, is not opposed to such a mechanical, stereotypical, and habitual repetition, but it embraces this standardized production of the commodity to expose its limits and extract what is differential and virtual within it. The task of art is to open a "line of flight" (ligne de fuite) that passes from the virtual to the actual by interrupting repetition with a difference. Gradually, repetition is transformed from the repetition of the return of the same to creation based in difference. The contemporary artist, Matthew Ritchie's repetitions that involve his process approach to drawing, is an appropriate example (Screen images 2.3 and 2.4 were taken from the PBS Art:21 featured segment on Ritchie called 'Structures'). Ritchie works with a computer program that enables him to play with fractal spaces. He can enlarge drawings, manipulate them, and further turn them into sculptures. Each time the installation travels to a new gallery, a difference 


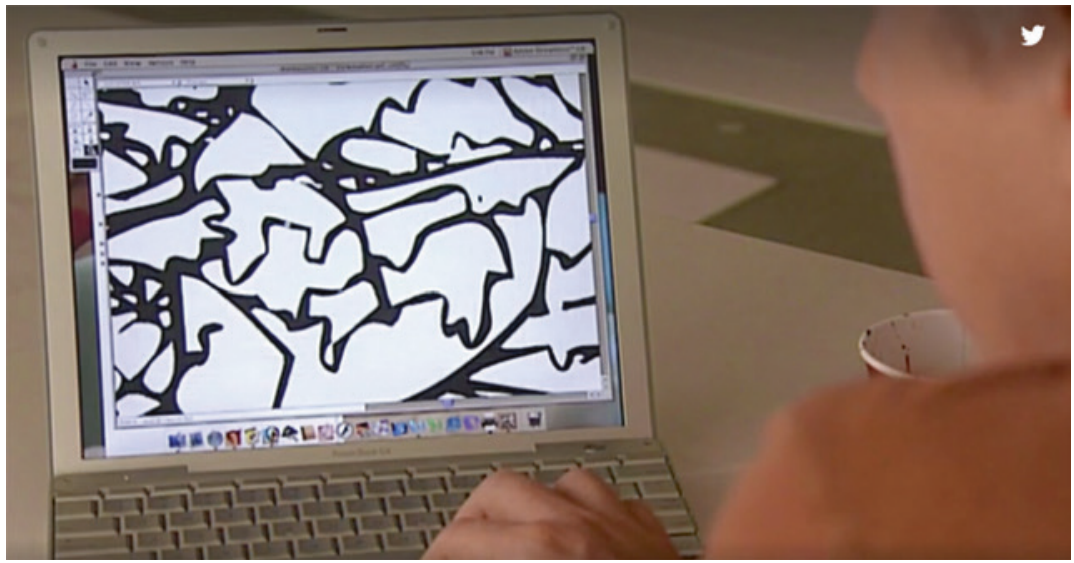

Screen image 2.3 Matthew Ritchie, PBS Art:21, 'Structures'

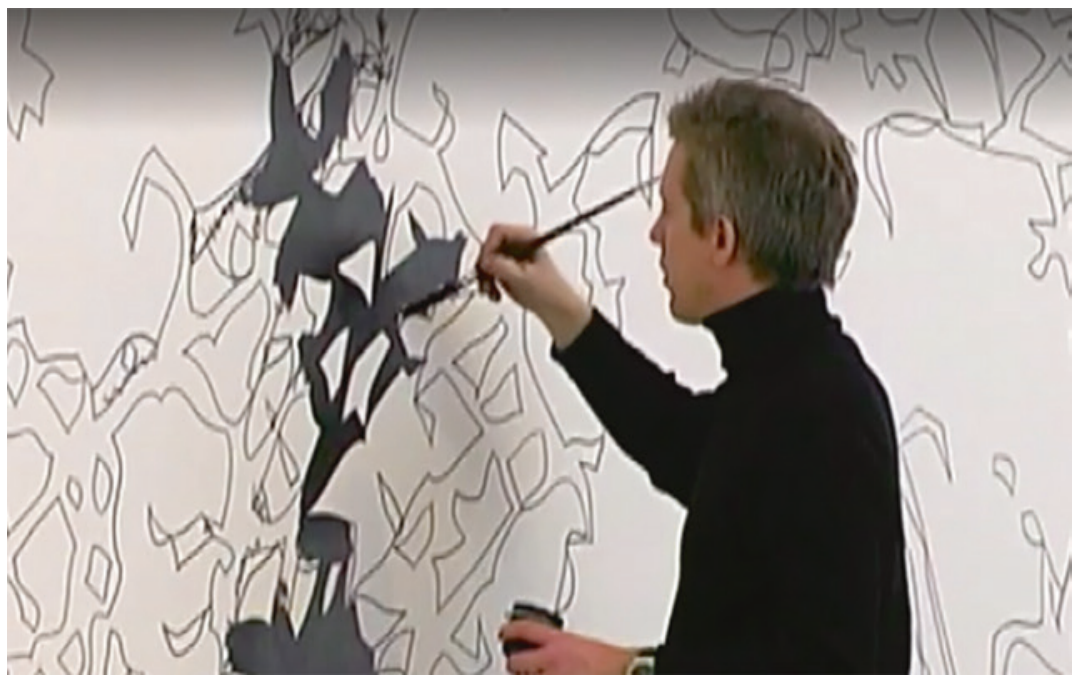

Screen image 2.4 Matthew Ritchie, screens PBS Art:21, 'Structures' 
has been introduced to the point where the exhibition itself has morphed into something different. Richie's 'play' with drawing enables a de-anthropocentrism to take place as human scale is no longer a viable measure. The assemblage consists of the computer program, Richie, as one of many assistants who rework the installation each time, and the new gallery space he is assigned. Completing each renewed assemblage are viewers who are thrown into a rhizomatic web of lines that never seem end.

Virtual in the Deleuze|Guattari lexicon does not mean 'virtual reality'-the 'virtual' as seen using special VR headsets or $3 \mathrm{D}$ cinema glasses. Rather, it refers to a realm of the invisible where memory and different orders and combinations of time are in play (past-future, present-past, present-future). These enfoldments of time are worked out in Deleuze's two cinema books (the movement-image and the time-image). Like Tao, or The Way, time is an eternal intuitive process, not chronological. The act of genesis does not have some set method. It is profoundly enigmatic. For instance, no one knows how or from where the 'blueprint' for the 'origin' of any species takes place. There are only speculations like those of the 'heretic' Rupert Sheldrake's (1981) 'morphic resonance' theory where a shared species memory is posited, perhaps located in the nowhere time-space of Aion, or Tao, being the dark matter and energy itself. Where do the morphogenic field instructions for cell growth come from to form an embryo? How does such self-organization come about? Epigenetic processes have put a damper to the jubilation on any claims to genetic determination. Either way, it is the virtual that is of key concern. Deleuze rejects the notion of the 'possible,' which remains attached to the logic of representation. It is an empirical event that will be actualized sometime in the future. It is based on prediction and calculation. Possible events are posited, then, depending on circumstances, one of them will be realized, but this a 'hedged' future. In contrast, Deleuze also maintains that the virtual is fully 'real.' The virtual "is not opposed to the real, it possesses a full reality by itself" (1994: 211). For genesis to occur, the 'real' multiplicity within the virtual must be actualized, which is to say, the potentiality of co-existent differences becomes 'real.' There is no predictability in this, only radicalized contingency as to how this virtual transcendental field is integrated or resolved. This is a true 'event' where the future has not been predicted; that is, evolution proper for Deleuze where the virtual is creatively actualized, whereas the possible is simply 'realized' (Deleuze and Parnet 2007: 148-150). This 
is simply to say that the possible 'real' is already preordained either through limitation or resemblance of a preconceived image as to what is about to happen. Following this logic, Deleuze (1988) can say in his book on Bergson that the 'virtual' is not opposed to 'real' but opposed to 'actual,' whereas the 'real' is opposed to the 'possible.' Repeating his Proust formula, he says that such states of virtuality are "real without being actual, and ideal without being abstract" (96). The creative event belongs to the Real as an actualization of something new.

The artist draws on an Event that has moved him or her. This Event is a disruption of chronological time; it belongs to cosmic time. The artist draws from cosmological forces - the rhythms of 'A Life' or Zoë. These terms are used interchangeably as in Deleuze's last monograph called Pure Immanence: Essays on a Life (2001). Zoë is unbound creative energy as inorganic life (it has no organs). This is like the Tao of the 'Uncarved Block,' which is capable of infinite characterizations, all possible ordered worlds, what Deleuze calls univocity. The Tao Te Ching, the main text of Taoism uses the term 'Pu' as this 'Uncarved Block': all nature is as its most powerful when considered in its original form-as energy (or Zoë), which would be quite consistent again with PLURALISM $=$ MONISM, monism being equivocal to $\mathrm{pu}=$ uncarved block as the virtual of potentiality for multiple actualization, not unlike the concept of a 'perfect quantum vacuum.'

\section{SimULACRA}

Another example of simulacra is in order as developed by Gregory Minissale (2013). Everyone is familiar with Duchamp's infamous Fountain, his ready-made that put to question art 'outside' the sacred halls of the gallery or museum. Unfortunately, his Fountain was destroyed, but he also miniaturized it hundreds of times, 300 times to be exact in his Boite-en-Valise (1935-1941) series. The Box in a Suitcase began as a 20-box edition. It then went through a further 6 editions of 20, until the final series was completed in 1966. This sequence of Duchamp's art process is a precursor to the developments Deleuze discusses in Difference and Repetition in 1968. Duchamp raised concerns over the copy or facsimile in an age of reproduction, which has only intensified in our digitalized age. The 69 miniatures of Duchamp's work that are reproduced in the suitcase are meticulous replicas of his oeuvre. It took 23,000 reproductions and the development of a new laborious 
process of replication to 'copy' his work over the span of 6 years. This was to be the 'end game' (like the chess that he loved so much) of the idea that a gallery and a museum were the custodians of unique original works of art. Duchamp offers a strange autobiography where his past works are preserved, yet an impossible equivalence is maintained between the original and the copy, where A and A' are 'different' only because, $\mathrm{A}^{\prime}$ (as a perfect clone) is displaced only by space and time. It is the Idea or the problematic that Duchamp wishes to 'preserve' by embracing the copy or multiple, which now becomes an uncanny simulacrum, like the difficulty of telling a recording from someone actually singing. Duchamp, in effect, was articulating what Deleuze was to do by overturning the Platonic distinction between original, copy, and simulacra wherein the Idea of an essentialized ideal reality - a superior realityjustified the judgment of inferiority. Identity prevails. Copies as icons most closely resembled the eternal Idea, whereas simulacra in which no semblance was found were the most inferior. Deleuze transformed this Platonic Idea as an intensive multiplicity. "Overthrowing Platonism refers to allowing simulacra to assert their rights over icons or copies. The motive of Platonism is to distinguish essence from appearance, the intelligible from the sensible, the Idea from the image, the original from the copy, the model from the simulacrum" (Deleuze 1983: 47).

Deleuze's simulacrum is not a false copy, nor is it a lack of similarity; rather, it is an image without a resemblance to a model. Simulacra have internalized differentiation, or difference-in-itself as justified by an 'eternal return,' wherein difference in kind, not degree, occurs. Intensity changes and is actualized differently. The Platonic Idea now becomes a virtual multiplicity, a chaosmosis of differences. It is qualitative multiplicity. It cannot be divided up without changing its nature as its intensity would then change. It is continuous, non-numerical, subject to change whenever it is divided. But, there is also a quantitative or external multiplicity: discontinuous, measurable, and calculable. The Idea as a virtual multiplicity forms various problematics, which are actualized through a process of differenciation where numerous differences in kind are created by its movement. Differenciation refers to the processual virtual content of an Idea. In contrast, Deleuze reserves the word differentiation for quantitative multiplicities of representation. Ideas, the power and potential of thinking as such, unfold a never-ending creative problematic. This problematic is only realized 'after the fact': looking back as much as forward. In Tao, the Way forms a visible trace through sensation. The 
virtuality of the problem is revealed, so to speak, by the conditions that were in place. The Idea of the Anthropocene, for example, is of great concern. It forms the current problematic.

While the above discussion is complex, it helps to grasp Duchamp's problematic; his Idea of asking about art its own status, and it brings us back to repetition with a difference. I draw on some remarks by Alain Badiou (2008) on Duchamp here to make my points. Part of Duchamp's anti-retinal and anti-romantic problematic was the idea of the "infra thin," "to pass into the infra thin interval that separated two identical things." This is the foundation for his use of reduplication, copies, and multiples that constituted his reputation. He would sign a copy, or a miniature or a multiplication of one of his works by the famous inscription "certified true copy," even when done by an assistant. The infra thin is a point of minimal discontinuity from the same to the other same. As Badiou says, "The new productive and reproductive thought must pass by this point." This point, then, belongs to the Tao of the immanent plane, the in-between, the middle-of-things, the rhizomatic line of flight, the infinite regress between 0 and 1 of complex numbers, like the square root of -1. It is the same concept as Paul Klee's Graupunkt, the grey-point of chaos. The Graupunkt is cosmological and virtual. It is the point before color establishes itself, the Tao of Color, like the pre-Plank universe. Duchamp's Idea is not 'embodied' in the artwork, or by his oeuvre. It is there 'on the surface,' like the Way is 'on the surface,' but at the infra thin "point that separates that being-there from itself." It is but a touch, a trace.

Simulacra and repetition take on yet another twist via the writings of Jacques Baudrillard (1983). His claim was that we had entered an age of hyperreality, a world of simulacra - a copy of a copy, or a hyper-copy where artificial rubber trees have stronger scents in Disneyworld than they have in nature. However, this is not the simulacra of Deleuze. It is the affect or the 'force' of the artwork that begins to matter. Deleuze in 1968 was heading in the same direction as Duchamp, as were Fluxes artists who continued this line of thought. André Malraux's "museum without walls" presents a similar idea: in the twentieth century, images become uprooted from their geographical contexts and can be organized purely along stylistic grounds. The entire history of images becomes a virtual past that then allows both cross-cultural and transcultural (that is global) comparisons among artists to take place. Deleuze picks up on this as well through the writings of Henry Bergson. Images are now put on a virtual 
plane, and in a similar way, Walter Benjamin's "optical unconscious" drew on the idea that images have been released from site specificity, to "any place whatsoever." Baudrillard's simulacra become a world of screen images; his "precession of simulacra" meant the blurring of true|false, real|imaginary. Simulation begins when opposites collapse. This brings to fore a whole new problematic.

Duchamp's Fountain can no longer be held up as an original. When we look at the variety of T-shirts that are found advertised on the Internet (Screen image 2.5), these are obvious tacky imitations reproduced commercially, we immediately wish to dismiss them as just cheap copies-mere simulacra following the Platonic aesthetic. Yet, the "T" shirt raises the same status of art that Duchamp's Fountain did. Underneath it says, "The great attack on the institution of art." The T-shirt is not found in an art gallery or institution, while Duchamp's mass-produced urinal is, and yet both the urinal and the T-shirt are mass produced, mundane objects, one referencing the status of the other. The T-shirt raises the same issue about the status of art as Duchamp's Fountain. It raises the questions about identity (jokingly it can be an invitation to urinate on it) and status of fashion discourse in relation to

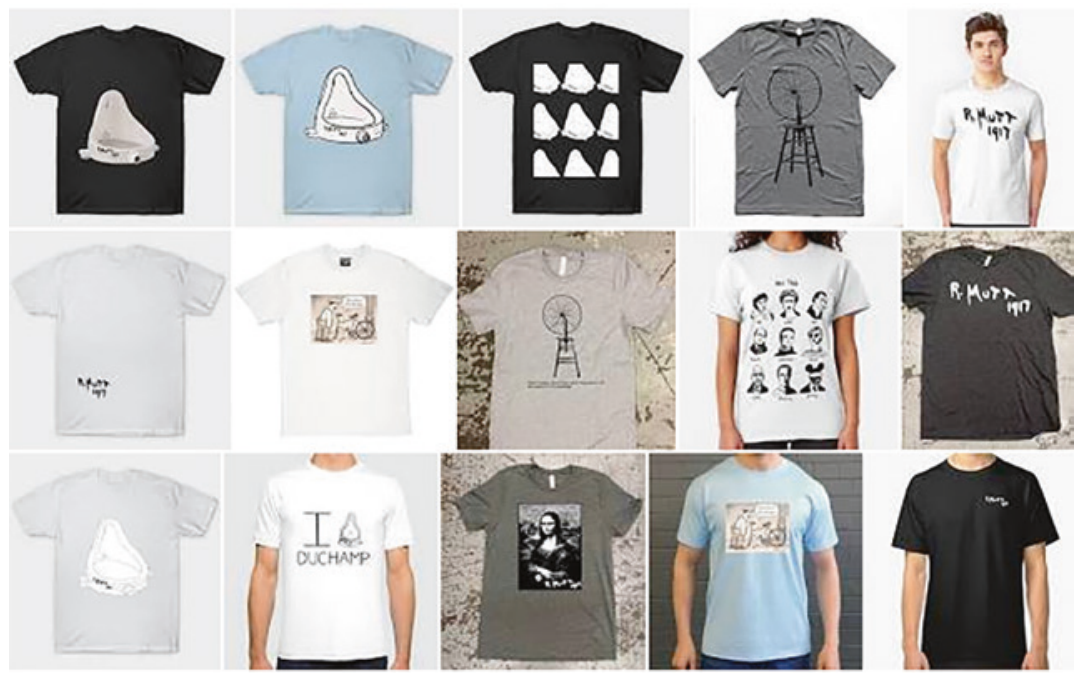

Screen image 2.5 Duchamp T-Shirts, screen image 
body and self-image. The T-shirt is a simulacrum; it takes its Idea from Duchamp's Fountain and sets it in motion to the realm of fashion, uncomfortably destabilizing the world of ordinary objects and the world of art.

A "Fountain dress" (available on the Internet), designed and copyrighted by Philip Colbert, offers another example of the Duchampian Idea. The concave urinal, a container for oncoming urine, is presented as being visually the opposite of a full pregnant woman's belly when placed on this model and worn like a dress. The sexual joke of the model having a penis is also evident as the drawing of a pipe that drains the urinal is placed directly below the model's waist emerging from her pubic area. What is this dress performing? What are its affects when worn in public, or even on a model runway? This can lead to many misogynistic and homophobic examples of Duchamp's Fountain, all repetitively exploring the Idea in a variety of representations. There are a number of examples to cite here. Meike van Schijndel has designed a "Kiss Urinal," essentially a woman's open mouth with full-bodied crimson-colored lips that forms the urinal itself, with two white teeth showing on the top lip. Its implications are pornographic, alluding to 'water games.' There is also a 'Jaw urinal.' Imagine the dark open mouth of a shark with long razor teeth. I gather that male urination in this case is both out of fear and against fear itself. There are outright misogynistic urinals as well: quite literally a urinal is placed between a model of a woman's outspread legs, as if the urinal was an exaggerated vulva (see image 3, https://www.oddee.com/item_97723.aspx). The 'Holy Mary' urinal is a half bust of the Mary figure; the male urinates into the cavity of her chest (image 4, same website). There is also a homophobic urinal that has a contorted male figure with testicles and erect penis, his hands seem to be spreading his anus, while his feet are vertically in the air (https://imgur.com/gallery/qxtJOTa). I encourage the reader to find these urinal designs on the Internet or to go to the websites I have listed.

So here we have a series of simulacra that are ethically worrisome as they perpetuate a male|female binary. These urinal variations become a never-ending loop, a form of representation where no difference is allowed in, no Duchampian 'infra thin interval' at play. The public toilet becomes a marginal space, personal and yet shared, to spread hate and division among gender and sexes. The Tao of Yin and Yang seems perverted rather than complicated. Each play of Fountain, as simulacrum, introduces a difference, which parodies the Idea of art in an 
"age of mechanical reproduction," to echo Walter Benjamin's wellknown and studied essay. There are many, many more variations of the urinal. When the urinal becomes a self-repeating loop, an eternal binary that shuttles between male and female, simply an object where a female is to receive a mouthful of urine or her vaginal filled by male urine, then difference in the Deleuze|Guattrian sense is not possible as the dualism plays into the same/difference of representational thought. There is no 'difference' that makes a difference in any of these examples: again there is no thought-provoking interval that might lead us into the cosmology of sex, the yin-yang of Tao, or difference-in-itself that Duchamp's Idea problematizes. As Deleuze puts it, an Idea is "neither one nor multiple, but a multiplicity constituted of differential elements" (Deleuze 1994: 278). In contrast, Korean director Kim Ki-duk's film Dream (2008) problematizes Yin and Yang forces (see Chapter 5 for this exploration). However, Sherrie Levine's Fountain (Buddha) (1996) might be an exception here as well. Copyright prevents me from showing you the image, but I encourage you to look it up on the Internet. The sculpture is clearly a parody on the shape of Duchamp's urinal as a 'significant form.' The urinal looks like a 'sitting' Buddha. She seems to be riffing on Duchamp's Buddhist leanings when thinking outside the box, at the same time it is made of shinning brass - as if gold, suggesting that Duchamp has also profited from his transgression making it a 'golden commodity.' The paradox is that Duchamp introduces a Taoist Idea, yet it remains caught by the simulacra of capitalism. Of course, there is a lot of nonsense spoken about this piece, which adds to the nonsense that I am providing - the best being that Levine is alluding to Brancusi's bronze sculptures who Duchamp mentioned when referring to his own urinal. It seems the blatant allusion to Buddha drops out in such formalist analysis that dwells on artistic genealogies.

\section{Powers of the False}

The simulacrum dispels any form of representational truth or essence or category of an object or thing, and works with what Deleuze calls the "powers of the false," where the only truth is time itself; that is change, the "eternal return of difference" as theorized by Nietzsche, where and when the new emerges. Lacan made the same differentiation between Wiederholung and Wiederkehr, only the latter brought a 'true' change. What is significant for art and its education is that a Deleuzian approach 
is always concerned with becoming, but a becoming-Other. How might it be possible to break the categorization of an object through art? This is a huge challenge. One way to break with representation is to place the object in such an arrangement or frame or modification so that the object or thing takes on a 'supplementary dimension'; sides of existence emerge that were never seen before or thought of before, like Mathew Barney's strange cremaster cycle of films, for example, that explore the inner workings of the male cremaster muscle that raises or lowers the testes in response to temperature. The object is made strange, abject, or made to tell a story never imagined before. The object is made to do what it was never imaged to do, or show its secret life-that is, its other life to produce a seeing that is beyond the object's everyday existence as we know it. In other words, other qualities of the object, what Deleuze calls its virtual multiple dimensions, are exposed. He called this a shift from the object to the objectile, from the subject to the superject, and from essence to event (Savat 2009).

All objects are "part-objects" in this sense, so the usual representational understanding of 'object' is mistaken. An object is always in flux, never stable, always in process and elusive. When such an object becomes strange, Lacan referred to it as objet a. It is alluring, strange, coming from the Outside, magical in its own way. Part-objects are always formless and functionless, composed of particles that increase and decrease at various speeds and intensities. They are cosmic in this sense, like those allusive elementary quark particles that are mathematically posited, but are yet to be 'discovered.' Such an understanding of 'object' follows the Taoist saying: "Though formless and intangible-It gives rise to form; Though vague and illusive-It gives rise to shapes; Though dark and obscure-it is the spirit, the essence, the life-breath of all things" (Lao-Tzu, Verse 21) (Lao-Tzu and Takuan Sōhō 2010). In a Deleuzian saying (coming from Spinoza): "We never fully know what a body can do," or what it is, or how other bodies affect it, or how it affects other bodies when placed in different assemblages. Let me show you two examples of this as related to visual culture. We all know that bottled plastic water damages the environment. The Coca Cola Company is the worst offender but does everything in its power to claim it is concerned about water for the earth. It is difficult for people to stop drinking bottled water, especially in the West, which already has good quality water. How could art intervene in such a problematic, a term Deleuze|Guattari use, for there are no easy solutions? 
The first example is directed at commodity culture. Duchamp's repetition and infra thin point are used effectively in a creative way. Seattle-based artist Chris Jordan in his exhibition Running the Numbers $I$ and $I I$ has tried to intervene in this problematic by exposing the waste in our throwaway capitalist economies so that the numbers of thrown away commodities become sublime and incomprehensible for us to grasp. We are unable to imagine the number of thrown away goods that happens every second of every day. The numbers become non-representable. His illustrations transport the viewer to this place of incomprehensibility; they become cosmic equations of the Tao. I encourage the reader to view Jordan's website to view the many examples that startle you as to how wasteful capitalist commodity societies are. In one such image, 426,000 phones are shown that are thrown away each day in the United States. Through repetition and miniaturization, these objects confuse the anthropocentrism of scale that keeps the frame of art together. Jussi Parikka (2015) called this state of affairs the Anthrobscene rather than the Anthropocene. The rare minerals needed to keep the technological machinery in production are likely to run out.

The second example is an artistic intervention into this ecological problematic: advertisements that are part of the Filter For Good campaign. I encourage the reader to go on the Internet and look at the images for this campaign. You will see two portraits of a man and a woman with black tar running out of their mouths, onto the white T-shirts they are wearing. These advertisements encourage you to drink filtered water and try to precisely intervene in our throwaway society of bottled water by showing a side of plastic we don't realize. It is an 'assemblage' that recognizes the agency of plastic as a petroleum product, which is made of tar, and tar is shown in these images as an abject object that is not to be swallowed. Yet, it appears that we have done so inadvertently, and it is now oozing out of our mouths on its own. Plastic becomes transmogrified (mutated) so that as an object its affects are felt at the deep level of our nerve-body, what Deleuze|Guattari called a Body without Organs (BwO). These images make us hesitate and (potentially) stop drinking water out of a plastic bottle. Plastic becomes more 'nonhuman' in the way it interacts with us; at the same time, its agential force is recognized as it has now become visible and materialized. It becomes an agent in its own right as it acts on us. This is what Deleuze|Guattari call an assemblage, when the human 
and the nonhuman come together in a form that is entirely unexpected. Heterogeneous elements combine in this case to present a repulsive affect. They encourage a political strategy where striated space, that is, space that is already occupied by the Coca Cola Corporation is intervened by a 'smooth space,' an opening that introduces difference into an already occupied and full molar assemblage. One can say that this intervention is an n-1 that opens up a new space and time. Again, this is a Taoist move when we read "The most yielding thing in the world will overcome the most rigid; the most empty thing ... will overcome the most full" (Lao-Tzu Verse 21, Verse 52) (Lao-Tzu and Takuan Sōhō 2010). There is always a way to the Outside to force thought. Plastic as a petroleum product becomes an objet $a$ in Lacan's terms.

\section{Becoming Imperceptible: Nomadic}

The subjectivity of the artist, for Deleuze|Guattari, is not one that elevates the ego; rather, it is a subjectivity of what they call nomadic becoming-to rid the "self" in such a way as to become imperceptible'-that is, to become someone who falls outside the usual categorizations, and who creates possible worlds through their art, provoking sensibilities that enable encounters of another 'compossible world.' Duchamp was such a nomad. Deleuze calls on Jorge Louis Borge's story "The Garden of the Forking Paths," where the Chinese philosopher, Ts'ui Pên, presents the Tao of the myriad of bifurcating paths that can be followed. Of course, as a virtual multiplicity, they are all simultaneously available, like all colors are available at the Graupunkt of Klee's color theory. Incompossibilities and dissonances that the virtual real presents have to be 'walked' by the nomad to find the Way. There is always an attempt made to be attuned with the world in Deleuze|Guattari terms, and this is very Taoist attitude. To become 'imperceptible' as an artist means constantly being attuned to difference in the world, what Deleuze|Guattari call 'signs' that affect you when the world looks at you, rather than you looking at it. Something from the Outside forces thought.

Some artists, as we know, use their own bodies as a technology of self-knowledge to become nomadic and imperceptible. I think here of the famous performance artist Orlan in this regard. For example, in her 'self-hybridization series' (Internet image search: 'Orlan, self-hybridization series' will generate an array of these images. 
Copyright prevents me from inserting these examples into this chapter), Orlan tries to confuse any notion of racial, national, and ethnic hybridity by playfully generating possible visions of beauty that remain outside of Western consciousness. She brings in identity elements of beauty from other cultures like the long-ringed necks or flat small noses. These hybridizations are compossible worlds. In this way, Orlan goes against what Deleuze|Guattari call the "faciality machine" as developed in TP, the way we are always produced and coded as signifying subjects into various categories so that a meaningful and stable world is maintained, like the Benetton advertisement I spoke of earlier. Beyond the face lies altogether a different inbumanity and different modes of organization that form strange new becomings. Orlan explores this inhumanity. She becomes a "probe-head" in Deleuze|Guattari's terms (TP, 190-191, O'Sullivan 2006; Mills 2015). Such a probe-head is cosmic as well; it belongs to the Tao of the Face, or in François Laurelle's terms to the 'generic human.'

Artists, according to Deleuze|Guattari, try to work with blocs of percepts and affects emerging from the transcendental Cosmic plane so as to impact and shake up our commonsense perceptions. They do so, so that the duality of subject and object can be overcome via creative becoming; the same principle as Yin |Yang where the Yin as passive nonbeing is equated to the Deleuzian understanding of the virtual and Yang, as the active being is equated with the actual. These two forces are also analogous to the qualitative and quantitative multiplicities. Let me explore this through a well-known Korean contemporary artist, Myoung Ho Lee, working in Seoul who explores the Tao of trees. She isolates trees in such a way that we see 'tree' again as a singularity. (Internet Image search: 'Myoung Ho Lee tree' will generate an array of these images. Copyright prevents me from inserting these examples in this chapter.) A singular 'tree,' by being extrapolated from its environment and then photographed, raises questions of scale and interconnectedness with Nature. They take on a singularity in their personalities, a materialist vitalism of spirituality that Deleuze argues is part of the plane of immanence as the membrane of the Cosmos. Each photographed tree is like a cosmic Dogon egg as Deleuze|Guattari discuss in TP (164). Each tree is a BwO. It is both permanent and impermanent at once, under constant transformation, which itself is a permanent process. 'Treeing' presents this very paradox. The tree's seed contains both its existence and non-existence, like the embryo discussed 
earlier; like the Dogon egg. In the Taoist sense, each tree has its own te, or virtue, its own intrinsic excellence. The notion of 'site' specificity of Lee's trees disappears and it becomes (in the Deleuzian sense) "any-site-whatsoever," raising questions about the empirical world as such. Each thing has its own internal and immanent order. The Idea of tree is not transcendentalist and not Platonic; rather, the Idea of tree becomes a singularity: its own order. Yet, its seed bears its existence and non-existence at once; it is both Nothing and Everything bringing us back to the Tao of Tree.

It is a series, again repetition, that preoccupies Lee's photography (refer to Internet image search). The series, another Deleuzian concept, requires that each tree, like the Duchampian urinal series that constitutes his 'strange' autobiography, introduces a difference. One cannot help but think of the Japanese art of Bonzai. As Lao-Tzu wrote in the Tao Te Ching: "Seeing your own smallness is insight" (Verse 52) (Lao-Tzu and Takuan Sōō 2010). Bonzai-ing the natural environment through serialization amplifies it by repetition to make a new imaginary field. Such an installation shifts the corporeal scale of the viewer to see the order of tree differently, perhaps rhizomatically. Bonzai $=$ the Tree of Life as it is tended from generation to the next generation in potentially an unending succession (or serialization).

In much different way, Mark Dion's Neukom Vivarium is also a tree, a dying western hemlock tree. (Internet Image search: 'Mark Dion, Neukom Vivarium' will generate an array of images of this installation. Copyright prevents me from inserting these examples in this chapter.) It is perhaps the Western response to the care of a Bonzai Tree. Begun in 2004 and completed in 2006, housed in the Seattle Art Museum, it has received wide attention and shows the irony of how to maintain a 'dying' western hemlock tree by putting it on artificial life support systems within the confines of an art gallery. Once again, a smooth space is created within a gallery setting, and a pedagogical element is also a part of this installation to explore its newly developing ecosystems. The tree becomes das Ding [The Thing] through its isolation. The rhizomatic connection of the assemblage of creatures, microbes, and artificial greenhouse apparatus that keeps it alive once more vivifies the singularity and interconnectedness of things themselves, which Lee's tree so vividly shows. We can also point to Jean-Claude Didler's installation, Trapped Inside (2006) as yet another tree put on life support on the grounds of the United Nations Environment Programme located in Gigiri, Nairobi. This time the 
Warburgia Ugandensis (African Greenheart) tree was specifically selected because of its endangered status and its spirituality, holding a special place given its use in traditional medicine.

\section{Art as an Encounter}

There is a YouTube video of Myoung Ho Lee's Tree exhibition where a gallerygoer made a one-minute video. You can watch it at: www. youtube.com/watch?v=07LSo_ukndY. I use it to illustrate my next Deleuzian point. As you will see, what is startling is the scale of these images, but worse is that the spectator is rushing from photograph to photograph, merely recording these tree-images. It raises the question as to when art becomes an object of encounter. Pedagogically and artistically, the encounter has become more and more of a concern in consumer culture; consumers have become participants in order to become producers of their own desire; in other words, good corporate marketing solicits what their consumers want, and then sells these wants back to them to maintain their brand and market share. Desire in the capitalist order is shaped by lack as Lacan constantly reminded his audiences. When I brought my Volvo a few years back, I became part of the Volvo family that sold me a particular lifestyle primarily based on the idea that my Volvo was one of the safest cars around. Should I be in an accident, I would most likely survive. My Volvo is sold as a fetish object, a desirable commodity, which is precisely what capitalism does. The encounter I had to buy my Volvo was shaped by my desire for safety, especially in Canadian winters. This is not the encounter Deleuze|Guattari are interested in, and it is not the type of participation displayed on this video. Many gallerygoers simply take images of artworks with their cell phones never to look at them again.

An encounter with art depends very much on the participantspectator; something has to happen, something has to "look back at you." It's an encounter only when the object; or the world of things deterritorializes you so to speak. Lee's trees have to "speak" to you as signs. Such a moment can only be 'sensed.' Your time has to be thrown "out of joint" as Deleuze says: there has to be a desubjectification taking place; you as a subject have to be dissolved as you become in tune with that object in such a way that your common sense or frame of reference is somewhat shaken or even shocked. If the object is simply recognized, like in the above video, either through your imagination, or perception, 
then your experience becomes limited. You fall again into representation. My Volvo was such an object. I had seen many televised commercials as to its safety record and its performance in winter storms. With objects of recognition, we are reconfirmed and reaffirmed into everyday life as we understand it. There is no thought in the Deleuzian terms, only cognition supported by a feeling of security. An art object of encounter has to rupture this self-confirming mechanism. It performs a cut where a different kind of subjectivity might begin. This is again a Taoist principle, as a Deleuzian encounter means you try to dwell in its center as a form of emptying the 'self,' which is a becoming-itself of Tao. Deleuze calls this 'becoming-imperceptible.' In contrast, my Volvo supported by ego; it fed the image of a future accident or being struck in the snow. I became my own prosumer.

\section{EVENT}

Deleuze calls such an encounter an event. As one's world is ruptured another is opened up. Such a rupture need not be huge. It can be small, but then develop into something huge. Just like chaos theory that says a butterfly flapping its wings may cause a storm somewhere else on the earth, this is precisely what Deleuze|Guattari mean by their notion of event. Only when an event-encounter is responded to can you say the participant-spectator has been affected, changed at the unconscious molecular level. The notion of affect is very important here, and much has been written about it-as the so-called 'affective turn' in the West (Clough 2008). Deleuze|Guattari are all about the virtual intensity of the affect, the way the nerves are affected most at the unconscious and intrinsic body levels. This is where thought without an image can take place. Affect is something that happens to us below the level of language and the image. Often, we can call affect as life force of Zoë, Taoist for Chi, before it is captured into emotion, what has been called Bios, life energy that has been categorized or actualized. The event is able to rupture what Deleuze|Guattari call striated space and open up a smooth space, a deterritorialization of space and time so that thought can take place.

To generate affect requires an event. Let me introduce you to a spectacular example via the photographic work of Spencer Tunick (Internet Image search: 'Spencer Tunick, Aletsch Glacier, Switzerland' will generate this image. Copyright prevents me from inserting this example in this chapter). Spencer Tunick's (along with Greenpeace 
Switzerland) installation of a 'living sculpture' (hundreds of naked men and women) was situated in the Aletsch Glacier, Switzerland, on August 18,2007 . This mass of bodies, all huddled together, symbolized the vulnerability of glaciers under climate change. The site of the installation created a smooth space in the public domain of the National park, a domain that is rapidly changing so that attention can be brought to the state of global warming. An element of duration is also evident. The disappearing speed of the glacier and the time it took to set up such a photo formed a basis of comparison. They illustrate the speed and intensity of the ecological processes that were being explored. We could say that this was akin to Duchamp's infra thin interval.

By photographing a mass of nude bodies in various environments, Spencer Tunick's photographs attend to a non-representational sense of equality; for example, 5200 volunteers stripped in front of Sydney's famed Opera House during Australia's Gay and Lesbian Alliance Parade. Gay men and women lay naked with straight neighbors to deliver this message. (Turnick's photos of this event, 'Sea, Earth, Change' can be found on the Internet). Deleuze|Guattri's aesthetic is constantly about becoming; hence, the notion of commodity is always being questioned. It is what art can 'do' that matters; what's its force does is the educational question. What is its political and performative ethic? It is but one attempt to avoid the commodity structure of capitalism, and the forces of its capture. Such art cannot be 'hung' on a wall, sold, traded, and so forth. It tries its hardest not to be a commodity by 'disappearing,' becoming anonymous and imperceptible once its "forcework" has been done (Ziarek 2004). Relations affirmatively change here as wellthe relation with the inhuman glacier in Tunick's case, and the relations between the huddling mass, cold, and shivering naked bodies who are affected. One can imagine the exchanges that took place among this 'living sculptural mass' in relation to themselves and the emergent 'will' that this project manifested. The stark exposure of nude bodies raises many questions regarding human vulnerability. It is an event that can then be counter-actualized in Deleuze's terms, revisited for its transvaluational affects, to engage with its monumentalism as it addresses climate change, and our species vulnerability in the face of it.

Lastly, I want to end by describing another event where the commodity form disappears and an encounter can take place. Army of Melting Men by Brazilian artist Néle Azevedo is a repeated installation performed 
in Brazil, France, Japan, Italy, and Germany. (For images, please do an Internet search: 'Néle Azevedo's Army of Melting Men.' Copyright prevents me from including images in this chapter.) Each repetition is counter-actualized and introduces a difference, not unlike the expansive drawing installations of Mathew Ritchie mentioned earlier. Azevedo's installation addresses global warming and presents the precariousness of existence under climate change. 1000-1300 cast mold ice figurines, generically male and female, approximately 18 inches high, are placed on site usually on the steps of some well-known state building of legislative authority (but not necessarily) by a participating public. Like the melting of the Arctic ice in Greenland and Antarctica (sea levels will rise over a meter by 2100 ), these statuettes begin to 'disappear' as they melt-as quickly as 20 minutes. They are vulnerable and frail just like Turnick's sculptural mass of nude bodies. During this duration, the melting 'sculpturines' undergo subtle differences of form before 'becoming extinct.' Their inactivity as they melt away (not unlike Turnick's stilled nude bodies without gestured movement) speaks directly to the inactivity of humankind toward climate change. The sculptural minimalism and autonomy addresses 'every[man]' who cannot escape, regardless of class, wealth, and power, the impeding apocalypse. I would like to end this chapter by reiterating that there are many touchstones between Taoism and Deleuze|Guattari's philosophy. Creativity is always an invention to bring new life into the world for a "people to come" as Deleuze says. Art education must take seriously the ecological crisis we face today and both of these process philosophies can give us a meeting of East and West that is needed.

\section{REFERENCES}

Badious, A. (2008). Some remarks concerning Duchamp. The Symptom. Available at: https://www.lacan.com/symptom9_articles/badiou29.html.

Baudrillard, J. (1983). Simulations. New York: Semiotext(e).

Balibar, E. (1992). Is there a 'neo-racism'? In E. Balibar \& I. Wallerstein (Eds.), Race, nation, class: Ambiguous identities (pp. 17-28). London: Verso.

Bogue, R., Chiu, H., \& Lee, Y.-l. (Eds.). (2014). Deleuze and Asia. Newcastle upon Tyne, UK: Cambridge Scholars Publishing.

Butler, J. (1990). Gender trouble: Feminism and the subversion of identity. New York, NY: Routledge. 
Clough, P. (2008). The affective turn: Political economy, biomedia and bodies. Theory, Culture \& Society, 25(1), 1-22.

Deleuze, G. (1983). Plato and the simulacrum (R. Krauss, Trans.). October, 27(Winter): 45-56.

Deleuze, G. (1988). Bergsonism (H. Tomlinson and B. Habberjam, Trans.). New York: Zone Books.

Deleuze, G. (1990). Logic of sense (M. Lester with C. Stivale Trans., C. V. Boundas, ed.). New York, NY: Columbia University Press.

Deleuze, G. (1992). Societies of Control. October, 59, 3-7.

Deleuze, G. (1994). Difference and repetition (Paul Patton, Trans.). New York: Columbia University Press.

Deleuze, G. (2001). Pure immanence: Essays on a life (A. Boyman, Trans.). New York: Zone Books.

Deleuze, G., \& Guattari, F. (1983). Anti-Oedipus: Capitalism and schizophrenia (R. Hurley, S. Mark, \& H. R. Lane, Trans., M. Foucault, Preface). Minneapolis, MN: University of Minnesota Press.

Deleuze, G., \& Guattari, F. (1987). Thousand plateaus: Capitalism and schizophrenia (B. Massumi, Trans.). Minneapolis, MN: University of Minnesota Press. TP intext.

Deleuze, G., \& Guattari, F. (1994). What is philosophy? (H. Tominson \& G. Burchell, Trans.). New York: University of Columbia Press.

Deleuze, G., \& Parnet, C. (2007). Dialogues II (Rev. ed.) (H. Tomlinson \& B. Habberjam, Trans.). New York: Columbia University Press.

Elkins, J. (2001). Why art can't be taught: $A$ handbook for art students. Urbana: University of Illinois Press.

Galloway, A. R. (2014). Laruelle: Against the digital. Minneapolis, MN: University of Minnesota Press.

Graham, A. C. (Lieh-tzu) (1990). The Book of Lieh-tzu: A Classic of Tao [4th Cen. BC] (A. C. Graham, Trans.). New York: Columbia University Press.

Hanh, T. N. (1995). Zen keys. New York, NY: Doubleday.

Lao, T. (1963). Tao Te Ching (D. C. Lau, Trans.). London: Penguin.

Lao-Tzu \& Takuan Sōhō. (2010). Tao Te Ching: Zen teachings on the Taoist classic (T. Clear, Trans.). Boston, Shambhala.

Land, N. (2012). Dark enlightenment Manifesto. Available at: http://www.thedarkenlightenment.com/the-dark-enlightenment-by-nick-land/.

Maeng, H. (2017). Documentation art and Korean Bunche painting: An investigation of Deleuze's Transcendental Realism through the painting process (PhD thesis. Lancaster University.

Maeng, H. (2020). Use of Deleuze's process ontology. Journal of Visual Art Practice. https://doi.org/10.1080/14702029.2020.1742001. 
Maliavin, V. V. (2011). Self-forgetting and its history: A Taoist perspective on postmodern phenomenology. Aplinkkeliai. Available at: https://aplinkkeliai.lt/musu-tekstai/tekstai-kitomis-kalbomis/self-forgetting-and-its-history-a-taoist-perspective-on-the-postmodern-phenomenology/.

Meillassoux, Q. (2008). After finitude: An essay on the necessity of contingency (R. Brassier, Trans.). New York: Continuum.

Mills, C. (2015). Talking probe-heads: Escaping faciality in contemporary aesthetics. Available at: https://www.academia.edu/27006836/Talking_Probe-Heads_ Escaping_Faciality_in_Contemporary_Aesthetics.

Minissale, G. (2013). Duchamp's Fountain and Deleuze's repetition and difference. Drain Magazine. Available at: http://drainmag.com/duchamp\%E2\% $80 \% 99$ s-fountain-and-deleuze $\% \mathrm{E} 2 \% 80 \% 99$ s-repetition-and-difference/.

Moeller, H.-G. (2006). The philosophy of the Daodejing. New York: Columbia University Press.

Noys, B. (2014). Malign velocities: Accelerationism and capitalism. New York: Zero Books.

O'Sullivan, S. (2006). Pragmatics for the production of subjectivity: Time for probe-heads. Journal for Critical Research, 10(4), 309-322.

O'Sullivan, S. (2014a). A life between the finite and infinite: Remarks on Deleuze, Badiou and Western Buddhism. Deleuze Studies, 8(2), 256-279.

O'Sullivan, S. (2014b, September 12). The missing subject of accelerationism. Mute. Available at: https://www.metamute.org/editorial/articles/ missing-subject-accelerationism.

Parikka, J. (2015). A geology of media and a new materialism: In conversation with Annika Richterich. Digital Culture and Society, 1(1), 213-226.

Savat, D. (2009). (Dis)connected: Deleuze's Superject and the Internet. In J. Hunsinger, L. Klastrup, \& M. Allen (Eds.), International handbook of internet research (pp. 423-436). Dordrecht: Springer.

Sheldrake, R. (1981). A new science of life: The hypothesis of formative causation. Los Angeles, CA: J. P. Tarcher.

Snaches, N. G. (2019). New quantum structure of space-time. Gravitation and Cosmology, 25(2), 91-102.

Vellodi, K. (2019). Thought beyond research: A Deleuzian Critique of artistic research. In P. de Assis \& P. Giudici (Eds.), Aberrant Nuptials: Deleuze and Artistic Research 2 (pp. 215-232). Leuven, Belgium: Leuven University Press.

Vodka, A. (2013). The Tao of BwO: Deleuzian becomings in Kung Fu Cinema. Cinema: Journal of Philosophy and Moving Image, 4, 62-80.

Zhang, P. (2016). Deleuze and Zen: An interological adventure. Canadian Journal of Communication, 41, 411-441.

Ziarek, K. (2004). The force of art. Stanford: Stanford University Press. 


\section{Filmography}

Lone Ranger. (1949-1957). (USA). Creators: George W. Trendle and George W. George. Apex Film Corp., Wrather Productions.

Lone Ranger. (2013). (USA). Dir. Gore Verbinski. Walt Disney, Jerry Bruckheimer Films.

Structures. (2005). (USA) PBS:21, Matthew Ritchie, Season 3. https://art21. org/. 